


\section{About IJMA [last updated October, $\left.1^{\text {st }}, 2021\right]$}

$\checkmark$ International Journal of Medical Arts is the Official Journal of the Damietta Faculty of Medicine, AlAzhar University, Egypt

$\checkmark$ It is an International, Open Access, Double-blind, Peer-reviewed Journal

$\checkmark$ Published four times a year

$\checkmark$ The First Issue was published in July 2019

$\checkmark$ Published under the following license: Creative Commons Attribution-ShareAlike 4.0 International Public License (CC BY-SA 4.0). It had updated from the Creative Commons license [CC BY] in volume 2, Issue 4, October 2020 About IJMA

$\checkmark$ The Egyptian Knowledge Bank hosts the web site of IJMA

$\checkmark$ The Egyptian Knowledge Bank supports IJMA

$\checkmark$ IJMA follows the regulations of the International Committee of Medical Journal Editors

$\checkmark$ IJMA is indexed in the "Directory of Open Access Journals" [15 January 2021].

$\checkmark$ IJMA is indexed in J-Gate [29-6-2021]

$\checkmark$ IJMA is a member of the International Society of Managing and Technical Editors

$\checkmark$ Listed in "Index Copernicus", "Publons", "Academic resource index [ResearchBib]" "Electronics journal library", "Eurasian Scientific Journal Index", "WorldCat" Superstar Journal Database, and "Citefactor"

$\checkmark$ IJMA introduced to the search engine [BASE] through DOAJ

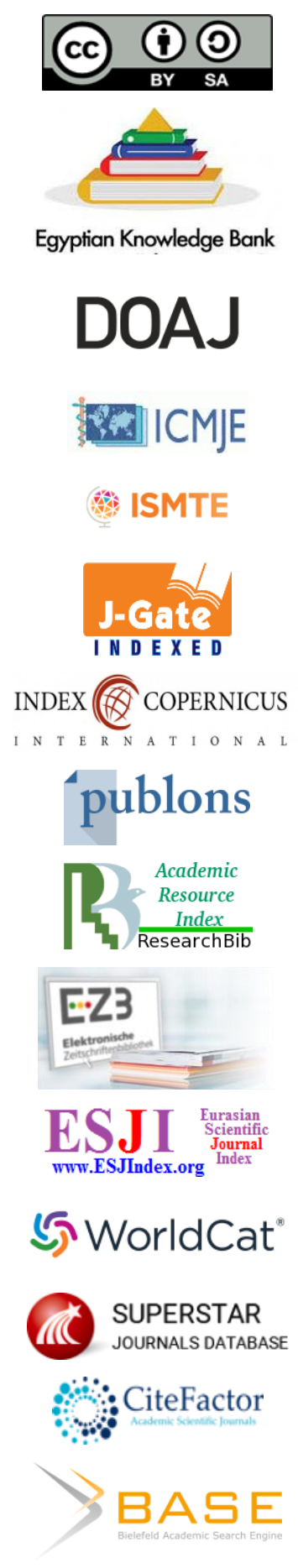




Available online at Journal Website
https://ijma.journals.ekb.eg/
Main subject [Cardiothoracic Surgery]

Original Article

\title{
Minimally Invasive versus Conventional Mitral Valve Surgery: Procedures and Early Outcomes
}

\author{
Mohamed Abdelkader Zaki [1], Ahmed Sobhy Emara [2], Yousry Elsaied Rezk [2], Bassem M. Aglan [2], Amr Allam [2],
} Ashraf M. Elnahas ${ }^{[2]}$

1 Department of Cardiothoracic Surgery, Damietta Faculty of Medicine, Al-Azhar University, Egypt

${ }^{2}$ Department of Cardiothoracic Surgery, Faculty of Medicine, Benha University, Egypt

Corresponding author: Mohamed Abdelkader Zaki

Email: mkaderzaki2020@gmail.com

Submission date: August 17, 2021; Acceptance date: September 19, 2021

DOI: 10.21608/IJMA.2021.91364.1353

DOAJ

\section{ABSTRACT}

Background: Minimal invasive mitral valve surgery gained wide acceptance. However, criticism continuous about its ability to replace the conventional full sternotomy technique.

Aim of the work: The study aimed to compare between the full sternotomy and less invasive approaches for mitral valve surgery.

Patients and Methods: The study recruited 100 patients. They were allocated to one of two equal groups [the traditional and minimal invasive approach]. All patients were thoroughly evaluated by history taking, physical examination, laboratory and ancillary radiological investigations. Assessment included incision length, weaning events, aortic cross clamp time, total bypass and operative times, rate of conversion from minimally invasive technique to full sternotomy. In surgical intensive care unit, ventilation hours, post-operative pain and need for analgesia, re-exploration for bleeding, blood loss and blood transfusion, and any complications were documented.

Results: Preoperative New York Heart Association [NYHA] class was significantly different between groups A and B. But, no significant difference was reported for patient demographic or preoperative data. The incision length and cross clamp time was shorter in A than B group [6.56 $\pm 1.88 \mathrm{~cm}, 61.78 \pm 35.91$ minutes' vs $12.54 \pm 1.78 \mathrm{~cm}$, and $78.08 \pm 36.24$ minutes, respectively]. Otherwise, the cannulation, bypass, operative times were significantly longer among group $A$. The ventilation, ICU stay, hospital stay, bleeding, serum creatinine and pain scores were significantly lower among group A. the postoperative events were comparable between both groups with slight increase of neurological events in A group [3 cases] than B group [2 cases]. At 6 months, both groups yielded non-significant difference, regardless of better outcome at direct postoperative time.

Conclusion: Minimal invasive mitral valve surgery had a good short and mid-term outcome as the conventional sternotomy approach. It could replace the conventional approach as a gold-standard for mitral valve surgery.

Keywords: Mitral Valve; Sternotomy; Mini-thoracotomy; Midline; Minimal Invasive

This is an open-access article registered under the Creative Commons, ShareAlike 4.0 International license [CC BY-SA 4.0] [https://creativecommons.org/licenses/by-sa/4.0/legalcode.

Citation: Zaki MA, Emara AS, Rezk YE, Aglan BM, Allam A, Elnahas AM. Minimally Invasive versus Conventional Mitral Valve Surgery: Procedures and Early Outcomes. IJMA 2021; 3 [4] October-December: 1835-1843 [DOI: 10.21608/JMMA.2021.91364.1353].

${ }^{*}$ Main subject and any subcategories have been classified according to the research topic 


\section{INTRODUCTION}

Surgery for mitral valve disease has evolved and a continuous rapid advancement is still enriching the field [1]. The median sternotomy has been the standard approach used in valve repair or replacement ${ }^{22]}$. However, the full sternotomy technique has been criticized for incision length, post-operative pain and possible postoperative comorbidities like wound infection and hemodynamic instability ${ }^{[3]}$. Thus, the minimally invasive mitral valve approach [mini-MVR] has gained wide acceptance and popularity. Many single center studies reported excellent outcome for mini-MVR. However, data are limited regarding real-world outcomes and costs [4-6]. Any operation uses a chest wall incision other than the standard median sternotomy is categorized as minimally invasive surgery. Right mini-sternotomy, robot-assisted right thoracic incision and partial sternotomy are examples of different incisions for minimally invasive surgery $[7]$.

The Mini-MVR surgery has been considered as a reasonable substitute to the traditional full sternotomy method with lower perioperative comorbidity and mortality. The rationale about the wide adoption of mini-MVR were the minimization of the surgical trauma, hastens the patient recovery, increasing patient satisfaction, and reducing the cost, without compromise of the valve repair or replacement approaches [8]. Techniques of mini-MVR aimed at reducing the complications of currently used large incisions, such as bleeding, pain, and risk of infection [9]. Furthermore, the MiniMVR approach showed high efficacy, satisfactory clinical outcome, better surgical field vision and surgical precision due to absent cannulae. In patients with chronic obstructive pulmonary disease [COPD], there is a high risk of sternotomy dehiscence; the sternum preservation conserves the breathing mechanics; the midline sternotomy approach is easily adopted by the most surgeons. There is no need for special instrumentation or a struggle for the depth of the operative field [10]. The principle goal of mini-MVR is performing the surgery with the same quality reported in traditional mitral valve surgery [through a median sternotomy] and without patient exposure to a higher risk [11].

\section{AIM OF THE WORK}

The current prospective study aimed to address a comparison between the traditional median sternotomy versus less invasive [mini-thoracotomy] approach in patients with mitral valve disease.

\section{PATIENTS AND METHODS}

This prospective comparative observational study recruited 100 patients who have submitted to elective first mitral valve operations. They were allocated to one of two equal groups [the traditional and minimal invasive approach].
Randomization was done immediately before the beginning of the operation so that group allocation was blinded to the patient. It was achieved by opening a closed envelope, containing a previously allocated letter indicating the surgical approach. Group [A] included 50 patients who have undergone a mitral valve surgery by minimal invasive surgery via the right anterolateral mini-thoracotomy. While group [B] included 50 patients who have undergone valve surgery by the standard full median sternotomy.

Participants were recruited between 14 January 2017 and 10 July 2020, at Benha University Hospital, Cardiac Surgery Unit in Nasser Institute, and EL-Sheikh Zayed Hospital. The study included patients who came for the first-time cardiac surgery with isolated mitral valve disease either stenosis or regurge. However, exclusion criteria included other cardiac conditions [e.g., ischemic or congenital heart diseases, diseases of the ascending aorta and diseases of other valves requiring intervention], chest abnormalities [e.g., pectus exacavatum or scoliosis], low ejection fraction [< 40.0\%], obesity [patients with body mass index more than or equal to $\left.30 \mathrm{~kg} / \mathrm{m}^{2}\right]$, poor pulmonary functions, huge left atrial dimension, previous chest trauma, thoracic surgery or pleurodesis, and peripheral vascular diseases.

Ethical considerations: The study was approved by the institutional review board [IRB] for research ethics, Damietta Faculty of Medicine, Al-Azhar University, Egypt [IRB 000123467-16-09-004]. A written informed consent was obtained from the patients or their relatives prior to admission with full explanation of the methodology used. The IRB approved the study and waived patient consent.

\section{Methodology}

All patients were evaluated preoperatively, intra- and postoperatively, and at the end of follow up time [6 months]. Preoperatively, a full history taking, clinical examination, laboratory, radiological, a twelve-lead electrocardiogram [ECG] was completed to all patients. In addition, an M-mode two dimensional with Doppler echocardiography and pulmonary functions were done for all participants.

The intraoperative evaluation included assessment of skin incision length, weaning events [inotropic support, DC shock], aortic cross clamp time, total bypass time, total operative time, and rate of conversion from minimally invasive technique to full sternotomy. In addition, all patients have been evaluated thoroughly during their intensive care unit stay for ventilation hours, post-operative pain and need for analgesia, re-exploration for bleeding, post-operative blood loss and blood transfusion.

Finally, the postoperative evaluation included chest X-ray [CXR], echocardiography, pulmonary function tests, 
measurement of patient satisfaction and pain scoring. In addition, morbidity and mortality were document. The morbidity included wound infection, developed arrhythmias, complication of femoral area, and lung collapse, and total hospital stay was determined. The six-months follow up included clinical evaluation for wound pain, scar, discharge, and disfigurement. Also, patient satisfaction, life style and daily activity were evaluated and documented.

The following definitions were used in the current work; inhospital mortality describes all deaths occurred within 30 days of surgery regardless the site of death [12]. The diagnosis of stroke was confirmed on CT or MRI by a neurologist. Renal failure was defined as the need for hemodialysis or increased serum levels of creatinine [13]. Any complications of respiratory system were documented, e.g., infection, failure of ventilation, reintubation or tracheostomy. Obesity was defined as body mass index over $29.9 \mathrm{~kg} / \mathrm{m}^{2}$ and graded according to the classification of the World Health Organization.

The NYHA functional classification of dyspnea was used for dyspnea identification and classification. On CXR, a normal Cardio-Thoracic Ratio should be $<0.5-0.55$. The closure time was set as the time extending between the end of cardiopulmonary bypass to the end of skin closure. The cardiopulmonary bypass time was defined as the time from skin incision to the beginning of bypass. Finally, the total duration of ICU and the hospital stay were documented [12].

Preoperative preparation and anesthetic technique: All patients received their morning dose of their cardiac drugs. A $10 \mathrm{mg}$ of intramuscular [IM] morphine sulphate was injected before the transfer to the operation room. In the preparation unit, a 14-gauge peripheral intravenous [IV] cannula was inserted under complete aseptic conditions. Sedation was achieved by $0.03-0.07 \mathrm{mg} / \mathrm{kg}$ midazolam. The radial artery [non-dominant] was cannulated by a 20-gauge artery cannula under local anesthesia. Two arterial blood samples were withdrawn; for baseline activated clotting time and arterial blood gas analysis. Monitoring started by five leads electrocardiogram [ECG], direct arterial blood pressure and pulse oximetry. The surgery was done under general anesthesia with common anesthetic technique and routine venous and arterial monitoring for both groups. The anesthetic maneuver was the same for all participants and consisted of Fentanyl 5$10 \mu \mathrm{g} / \mathrm{Kg}$, and endotracheal intubation was facilitated with the use of Pancuronium $0.02 \mathrm{mg} / \mathrm{Kg}$. Additional dose of Fentanyl 100-200 $\mu \mathrm{g}$ was administered if required. After full relaxation, oral intubation of the trachea was completed with an appropriate sized tube [double-lumen endotracheal tube was used in all patients by orotracheal intubation]. Anesthesia was maintained by isoflurane $0.5-1.0 \%$ inhalation. A triple lumen central venous catheter plus a single lumen one were inserted directly after induction. Intravenous access was achieved through the left internal jugular vein or left subclavian vein.
Left radial arterial blood pressure monitoring was utilized. The probe of the transesophageal echo, a urethral catheter, nasogastric tube and a nasopharyngeal temperature probe were also inserted. Finally, two external defibrillator pads were positioned on the chest wall outside the surgical field.

\section{Surgical procedure}

In thoracotomy group [A], the patient was positioned in supine position, and a pillow under the right scapula was used to elevate the right hemithorax. A $30^{\circ}$ left lateral position was instituted and the right arm was situated posteriorly. The right elbow was gently flexed, the right shoulder was abducted and the right forearm was fixed on the operation table to enable the right axillary midline exposure. The right scapula was supported by a sandbag-roller and the right buttock supported by another. The right hip was extended, and supported by a pillow. The chest, abdomen, and right groin were cleaned, and painted with iodine solution. Intraoperative transesophageal echocardiography [TEE] was used to guide the positioning of IV cannulation and for accurate assessment of cardiac function and the heart de-airing. Surgical incision was created through the right sub-mammary line [between the sternum lateral border up to mid axillary line]. In female patients, breast tissue was smoothly mobilized to permit access to the thoracic cavity through the right $4^{\text {th }}$ intercostal space. The pericardium was opened parallel and superior to the right phrenic nerve and retraction stitches were placed. Cardiopulmonary bypass was then established and after cooling, a long curved clamp was used to cross clamp the aorta and an aortic root cannula was used for delivery of blood cardioplegia. The interatrial groove was used to achieve the left atriotomy and the diseased valve was excised and replaced by a prosthetic valve through a continuous suture method. After positioning of the valve, left atriotomy was closed by a prolene [4-0] sutures and de-airing was achieved before the cross clamp removal. Weaning and de-cannulation were completed through a standard maneuver in both the groups, with proper hemostasis. A solution of protamine sulphate was used to reverse the action of heparin. The chest was closed in layers and two drain tubes were left in situ.

For group B, the operative steps were the same as for group A except the approach, which was achieved through the standard median sternotomy.

Perioperative management: Patients were monitored after surgery in the surgical ICU and moved to the surgical ward after hemodynamic stability. CXR and analysis of blood gases were done to rule out pulmonary comorbidities. A TTE was done before discharge, and at 6 months postoperatively to evaluate the postoperative status. Assessment of cosmosis, patient perception, pain and satisfaction were evaluated. Patients were electively ventilated up to the fulfillment of extubation criteria. Post-extubated patients were 
moved to step down unit. Oral anticoagulation was prescribed just after removal of the drain, and consisted of $10 \mathrm{mg}$ warfarin sulfate as a starting dose, followed by a daily dose of $5 \mathrm{mg}$. Prothrombin time [PT] was measured after 72 hours of the first warfarin dose and the dose was titrated to keep INR within 3.0 to 3.5. The intravenous antibiotics were continued up to the $5^{\text {th }}$ post-operative day, and then, there was a shift to oral antibiotics till patient discharge.

Statistical analysis: SPSS version 26 for Windows was used for statistical analysis. Statistical analysis was performed between the two groups using the Mann-Whitney test for parametric data and Fisher's exact test for nonparametric data. Arithmetic mean and SD were calculated. T-test was used to compare values. The X2-test was used for qualitative values. A significant difference was recorded if the P-value was less than or equal to 0.05 .

\section{RESULTS}

Preoperatively, both groups were comparable regarding age, gender, associated medical conditions, atrial fibrillation, laboratory data, echocardiographic findings and valve lesions. However, Group-B had significant difference NYHA class than group-A [in group $B, 0,26,22$, and 2 patients had class I, II, III and IV respectively; while in group A, 6, 33, 9 and 2 had class I, II, III and IV respectively] [Table 1].

The intraoperative findings revealed that, the minimal invasive group was associated with significantly shorter incision length, and lower cross clamp time. At the same time, the minimal invasive surgery group had significantly longer cannulation time, total bypass time, and total operative time. The type of operation did not differ significantly between groups [it was repair and replacement among 6, 44 patients in group $A$ and 12 and 38 patients in group $B$, respectively]. The need for DC shock was lower among group $A$ than group $B$ [10.0\% vs $22.0 \%]$. However, the difference was statistically non-significant [Table 2].

In the early postoperative period, the minimally invasive group had significantly lower ventilation time, ICU stay, total hospital stay duration, postoperative pain, bleeding, mean of transfused units, serum levels of liver enzyme [SGPT], and serum creatinine. However, the re-exploration was not significant between groups A and B [ $4 \%$ vs. $10 \%]$. Also, the postoperative events [atrial fibrillation, neurological events, and renal failure] did not differ significantly between groups, although AF and neurological events were higher among minimally invasive group. The CXR revealed significant high normality among minimally invasive than conventional group $[92 \%$ vs. $62 \%$ respectively]. Otherwise, the inotropic support was increased in minimally invasive than conventional groups, but no statistical significance difference. The ejection fraction also did not differ significantly between groups. Finally, the patient satisfaction was significantly higher among minimally invasive than conventional group [Table 3].

At 6-month follow up after surgical intervention, results showed non-significant difference between minimally invasive and conventional approaches regarding echocardiographic data, INR, the scar and NYHA class [Table 4].

Table [1]: Comparison between groups regarding patient demographic and preoperative data

\begin{tabular}{|c|c|c|c|c|}
\hline \multicolumn{2}{|c|}{ Parameter } & Group A [n=50] & Group B [n=50] & p \\
\hline \multicolumn{2}{|l|}{ Age [Years] } & $32.58 \pm 13.78$ & $35.86 \pm 14.28$ & 0.24 \\
\hline Sex & $\begin{array}{l}\text { Male } \\
\text { Female }\end{array}$ & $21[42.0 \%]$ & $27[54.0 \%]$ & 0.23 \\
\hline \multirow{2}{*}{ Diabetes mellitus } & Diabetic & $16[32.0 \%]$ & $11[22.0 \%]$ & \multirow{2}{*}{0.36} \\
\hline & Non diabetic & 34 [68.0\%] & $39[78.0 \%]$ & \\
\hline \multicolumn{2}{|l|}{ Body mass index $\left[\mathrm{kg} / \mathrm{m}^{2}\right]$} & $24.11 \pm 4.55$ & $24.76 \pm 6.73$ & 0.54 \\
\hline \multirow{3}{*}{$\begin{array}{l}\text { Preoperative NYHA } \\
\text { class }\end{array}$} & I & $6[12 \%]$ & $0[0.0 \%]$ & \multirow{3}{*}{$0.006^{*}$} \\
\hline & ॥ & $33[66.0 \%]$ & $26[52.0 \%]$ & \\
\hline & $\begin{array}{l}\text { III } \\
\text { IV }\end{array}$ & $\begin{array}{c}9[18.0 \%] \\
2[4.0 \%]\end{array}$ & $\begin{array}{c}22[44.0 \%] \\
2[4.0 \%]\end{array}$ & \\
\hline \multicolumn{2}{|c|}{ Preoperative atrial fibrillation [AF] } & $9[18.0 \%]$ & $13[26.0 \%]$ & 0.49 \\
\hline \multirow{5}{*}{$\begin{array}{l}\text { Preoperative laboratory } \\
\text { data }\end{array}$} & Bilirubin & $1.31 \pm 0.67$ & $1.13 \pm 0.62$ & 0.17 \\
\hline & Serum creatinine & $1.40 \pm 0.52$ & $1.56 \pm 0.41$ & 0.10 \\
\hline & SGPT & $27.72 \pm 12.78$ & $22.4 \pm 17.46$ & 0.08 \\
\hline & Hemoglobin & $12.44 \pm 1.947$ & $11.84 \pm 1.86$ & 0.12 \\
\hline & Prothrombin time [PT] & $12.06 \pm 1.93$ & $13.31 \pm 3.91$ & 0.06 \\
\hline \multirow{5}{*}{$\begin{array}{l}\text { Preoperative } \\
\text { echocardiography }\end{array}$} & $\mathrm{EF}$ & $57.44 \pm 6.49$ & $56.04 \pm 7.17$ & 0.32 \\
\hline & Left atrial diameter & $5.264 \pm 0.65$ & $5.132 \pm 0.75$ & 0.39 \\
\hline & Pulmonary artery pressure & $24.9 \pm 13.11$ & $27.1 \pm 11.02$ & 0.31 \\
\hline & ESD & $34.24 \pm 5.88$ & $36.6 \pm 8.24$ & 0.10 \\
\hline & LVEDD & $51.2 \pm 6.03$ & $49 \pm 7.15$ & 0.15 \\
\hline \multirow{2}{*}{ Valve lesion } & Stenosis & $25[50.0 \%]$ & $17[34.0 \%]$ & \multirow{2}{*}{0.11} \\
\hline & Regurge & $25[50.0 \%]$ & $33[66.0 \%]$ & \\
\hline
\end{tabular}


Table [2]: Comparison between groups regarding operative data

\begin{tabular}{|c|c|c|c|}
\hline Parameter & Group A [n=50] & Group B [n=50] & $\mathbf{P}$ \\
\hline Length of incision [cm] & $6.56 \pm 1.88$ & $12.54 \pm 1.78$ & $<0.001^{*}$ \\
\hline Cannulation time [min] & $34.44 \pm 3.12$ & $25.46 \pm 3.20$ & $<0.001^{*}$ \\
\hline Total by-pass time [min] & $128.84 \pm 52.90$ & $108.1 \pm 41.76$ & $0.032^{*}$ \\
\hline Cross clamp time [min] & $61.78 \pm 35.91$ & $78.08 \pm 36.24$ & $0.026^{*}$ \\
\hline Total operative time [min] & $268.16 \pm 77.86$ & $195.16 \pm 53.41$ & $0.005^{*}$ \\
\hline Type of operation & $\begin{array}{c}6[12.0 \%] \\
44[88.0 \%]\end{array}$ & $\begin{array}{l}12[24.0 \%] \\
38[76.0 \%]\end{array}$ & 0.12 \\
\hline Need for direct current [DC] shock & $5[10.0 \%]$ & $11[22.0 \%]$ & 0.10 \\
\hline
\end{tabular}

Table [3]: Comparison between groups regarding postoperative data

\begin{tabular}{|c|c|c|c|c|}
\hline \multicolumn{2}{|c|}{ Parameter } & Group A [n=50] & Group B [n=50] & $\mathbf{p}$ \\
\hline \multicolumn{2}{|c|}{ Ventilation time [hours] } & $5.38 \pm 2.76$ & $9.06 \pm 12.779$ & $0.047^{*}$ \\
\hline \multicolumn{2}{|c|}{ ICU stay time [hours] } & $29.9 \pm 15.43$ & $41.4 \pm 24.04$ & $<0.001^{*}$ \\
\hline \multicolumn{2}{|c|}{ Total hospital stay time [days] } & $6.04 \pm 1.22$ & $9.22 \pm 6.15$ & $0.007^{*}$ \\
\hline \multicolumn{2}{|c|}{ Visual analogue scale for pain } & $3.78 \pm 1.40$ & $5.62 \pm 1.08$ & $0.037^{*}$ \\
\hline \multicolumn{2}{|c|}{ Bleeding } & $276.2 \pm 136.90$ & $413.3 \pm 198.20$ & $0.005^{*}$ \\
\hline \multicolumn{2}{|c|}{ Blood transfusion required } & 1.46 & 2.1 & $0.002^{*}$ \\
\hline \multicolumn{2}{|c|}{ Re-exploration } & $2[4.0 \%]$ & $5[10.0 \%]$ & 0.21 \\
\hline \multicolumn{2}{|c|}{ Blood transfusion units } & $1.46 \pm 1.54$ & $2.1 \pm 2.55$ & $\left.0.003\right|^{*}$ \\
\hline \multirow{4}{*}{$\begin{array}{l}\text { Postoperative } \\
\text { events }\end{array}$} & $\mathrm{AF}$ & $6[12.0 \%]$ & $2[4.0 \%]$ & 0.49 \\
\hline & Neurological complications & $3[6.0 \%]$ & $2[4.0 \%]$ & 0.91 \\
\hline & Renal complications & $2[4.0 \%]$ & $2[4.0 \%]$ & 1.0 \\
\hline & Phrenic nerve injury & $0[0.0 \%]$ & $0[0.0 \%]$ & - \\
\hline \multirow[t]{5}{*}{ Postoperative CXR } & Normal & 46 [92.0\%] & $31[62.0 \%]$ & \\
\hline & Congestion & $0[0.0 \%]$ & $2[4.0 \%]$ & \\
\hline & Effusion & $1[2.0 \%]$ & $3[6.0 \%]$ & $0.002^{*}$ \\
\hline & Atelectasis & $0[0.0 \%]$ & $11[22.0 \%]$ & \\
\hline & Collapse & $3[6.0 \%]$ & $3[6.0 \%]$ & \\
\hline \multirow[t]{3}{*}{ Inotropic support } & No & $26[52.0 \%]$ & $29[58.0 \%]$ & \\
\hline & minimal & $24[48.0 \%]$ & $20[40.0 \%]$ & 0.46 \\
\hline & High & $0[0.0 \%]$ & $1[2.0 \%]$ & \\
\hline \multicolumn{2}{|l|}{ Postoperative SGPT } & $21.74 \pm 14.62$ & $32.42 \pm 31.23$ & $0.031^{*}$ \\
\hline \multicolumn{2}{|c|}{ Postoperative serum creatinine } & $1.394 \pm 0.43$ & $1.8156 \pm 0.76$ & $0.001^{*}$ \\
\hline \multirow[t]{3}{*}{ Wound infection } & Total & $4[8.0 \%]$ & $8[16.0 \%]$ & \\
\hline & Superficial infection & $3[6.0 \%]$ & $7[14.0 \%]$ & 0.35 \\
\hline & Deep infection & $1[2.0 \%]$ & $1[2.0 \%]$ & \\
\hline \multirow[t]{4}{*}{ Patient satisfaction } & Not satisfied [Dissatisfied] & $6[12.0 \%]$ & $13[26.0 \%]$ & \\
\hline & Not certain & $8[16.0 \%]$ & $11[22.0 \%]$ & \\
\hline & Satisfied & $29[58.0 \%]$ & $24[48.0 \%]$ & $0.037^{*}$ \\
\hline & Very satisfied & $7[14.0 \%]$ & $1[2.0 \%]$ & \\
\hline \multicolumn{2}{|l|}{ Postoperative EF } & $47.18 \pm 5.216497$ & $49.32 \pm 7.90102$ & 0.11 \\
\hline
\end{tabular}

Table [4]: Comparison between groups regarding six months follow up data

\begin{tabular}{|c|c|c|c|c|}
\hline \multicolumn{2}{|c|}{ Parameter } & Group A [n=50] & Group B $[n=49]$ & $\mathbf{p}$ \\
\hline Echocardiographic data & $\mathrm{EF} \%$ & $60.54 \pm 4.43$ & $61.67 \pm 5.42$ & 0.25 \\
\hline & LVEDD & $51.5 \pm 5.6$ & $5.3 .1 \pm 7.5$ & 0.23 \\
\hline & ESD & $34.4 \pm 8.68$ & $36.16 \pm 6.90$ & 0.26 \\
\hline & LAD & $4.56 \pm 0.64$ & $4.552 \pm 0.72$ & 0.946 \\
\hline & PAP & $27.74 \pm 11.31$ & $25.97 \pm 11.21$ & 0.43 \\
\hline INR & & $2.73 \pm 0.66972$ & $2.87 \pm 0.68$ & 0.30 \\
\hline Scar & $\begin{array}{l}\text { Normal } \\
\text { Keloid }\end{array}$ & $50[100.0 \%]$ & 48 [97.95\%] & 0.49 \\
\hline NYHA class & $\begin{array}{l}\text { I } \\
\text { II } \\
\text { III } \\
\text { IV }\end{array}$ & $\begin{array}{c}18[36.0 \%] \\
28[56.0 \%] \\
4[8.0 \%] \\
0[0.0 \%]\end{array}$ & $\begin{array}{c}20[40.8 \%] \\
28[57.1 \%] \\
0[0.0 \%] \\
1[2.0 \%]\end{array}$ & 0.16 \\
\hline
\end{tabular}

LVEDD: Left ventricular end-diastolic diameter, PAP: pulmonary artery pressure, ESD: End systolic diameter, LAD: Left atrial diameter 
DISCUSSION

In the current work, we aimed to compare two approaches [minimally invasive versus conventional] for mitral valve surgery, regarding the operative data, early and 6 month outcomes. Our patient population represented a homogenous sample. No significant difference was observed between groups $A$ and $B$ regarding patient age, gender or preoperative data, expect for the reported lower NYHA class among group $B$ than group $A$. Operative data revealed that, minimal invasive surgery had significantly shorter incision length, shorter cross clamp time, longer cannulation time, total bypass time, and total operative time. Postoperatively, minimal invasive group had significantly shorter ventilation time, ICU stay, total hospital stay duration, lower pain, bleeding, transfused units, liver enzymes and serum creatinine. Lung normality on $\mathrm{x}$-ray was significantly increased among minimally invasive than conventional group $[92.0 \%$ vs. $62.0 \%$ respectively]. Finally, the patient satisfaction was significantly higher among minimally invasive than conventional group.

In the current work, the minimum age was 8 years and the maximum age was 65 years. This widest age range may be due to higher prevalence of rheumatic heart disease, different life style, geographical variations, and genetic causes. The younger females favored right mini-thoracotomy approach for its better cosmetic outcomes. Ahmad Shah et al. [14] also reported that cosmetic results were better at thoracotomy group especially at young females who were satisfied with the appearance of the postoperative scar. Saha et al. ${ }^{[15]}$ and Ganie et al. ${ }^{[16]}$ reported overall slight female sex predominance as in the current work.

The current work results yielded non-significant difference between groups regarding echocardiographic data. These results are in line with previous studies. For example, Dokhan et al. [17] reported comparable results in a study of 50 patients, and Ganie et al. ${ }^{[16]}$ reported comparable groups with respect to LVEF.

Regarding the preoperative NYHA classification, El-Fiky et al. [18] reported comparable results with significant difference in the NYHA grade between the thoracotomy group and the sternotomy groups $[\mathrm{P}=0.03]$. Ahmad Shah et al. [14] reported 20 [63\%] patients in sternotomy group with NYHA class III, and the remaining $37 \%$ were in class IV and 24 [75\%] patients in thoracotomy group were class III while the rest were class IV. However, they reported no significant difference between the two groups.

Regarding intraoperative data, results are in line with previous studies. Dokhan et al. [17] reported a similar statistically significant difference between the two groups regarding length of the surgical incision [19.28 \pm 2.15 vs.
$5.96 \pm 0.84 \mathrm{~cm}$ in conventional versus minimal invasive groups respectively, $P=0.001$ ]

In our study, two patients in group [A] required conversion to median sternotomy due to suspected aortic root injury or dissection or for proper exposure of the mitral valve [their results had not been included in statistical analysis and replaced by another two patients, who completed the mini-approach]. This Conversion rate to median sternotomy was minimal, which is in concordance with other studies $[16,19]$.

The aortic clamping techniques are variable at right thoracotomy. We used the flexible cosgrove clamp in all patients of group A to avoid the risks and the additional monitoring of endo-balloon and for economic reasons. Ahmad Shah et al. ${ }^{[14]}$ used the direct long curved aortic clamp. Tang et al. [20] used the techniques, external cosgrove clamp or endo-balloon, according to the accessibility. Also Murzi et al. [21] reported at their propensity score analysis on 1280 patients that central cannulation with direct aortic clamping was better than femoral cannulation with endoballoon clamp that was associated with less aortic dissection and less neurological events at postoperative period.

The cross clamp time was significantly shorter among minimally invasive than conventional group [ $61.78 \pm 35.91$ vs. $78.08 \pm 36.24$, respectively; $P<0.05]$. These results were different from Tang et al. [20] and Mansy et al. [22] who reported non-significant difference between sternotomy and thoracotomy groups regarding cross clamp time $[P>0.05]$. Some reports showed shorter cross clamp time at thoracotomy group owing to easy accessibility to the left atrium even with small atrial size; as Ahmad Shah et al. [14]

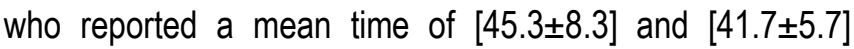
minutes in sternotomy and thoracotomy groups, respectively $[P<0.05]$.

The by-pass time and total operative time were prolonged in group A versus group B. Similar to our results Saha et al. [15] reported a significantly higher mean total operative time of [229.5 \pm 28.1 minutes] in Group I versus [197.8 \pm 45.0 minutes] in the median sternotomy group. In addition, Ahmad Shah et al. ${ }^{[14]}$ reported prolongation of total by-pass time in thoracotomy than sternotomy. However, the difference was statistically non-significant $[p=0.69]$. Raslan et al. [23] also showed significant difference of total by-pass time and total operative time between right mini-thoracotomy and sternotomy in atrial septal defect closure. Mansy et al. [22] reported a prolongation of total operative time, total by-pass time at sternotomy [246+34, 89 \pm 54$]$ than thoracotomy [180 \pm 24 , and $96 \pm 44][p<0.05]$. The study thought that difference reflects the times needed for opening and cannulation through sternotomy. 
In agreement with our results, Mansy et al. ${ }^{[22]}$ study showed significant difference between both approaches with higher incidence of post-operative bleeding and allogenic blood transfusion at sternotomy groups $[p<0.05]$. El-Fiky et al. [18] observed significantly lower postoperative blood loss in the mini-thoracotomy group $[481 \pm 142 \mathrm{~mL}$ vs. $930 \pm 357$ $\mathrm{mL}, \mathrm{p}=0.01]$.

Bleeding was minimized in group $A$, which was translated into less frequent surgical re-exploration and lower transfusion requirements. Two patients in the first group and five cases in the second group required re-exploration for bleeding or tamponade. Svensson et al. ${ }^{[24]}$ reported that less bleeding and lower blood transfusions are likely due to the less extensive mediastinal dissection required for the minimally invasive approach.

Minimally invasive, Group A showed a significant shorter mechanical ventilation period [5.38 \pm 2.77$]$ hours versus [9.06 \pm 12.77$]$ hours in conventional group $B \quad[p=0.048]$. El Ashkar and Khallaf [25] reported similar data where mechanical ventilation time was significantly shorter in minithoracotomy group [5.67 $\pm 1.63 \mathrm{~h}$ ] compared to sternotomy group [9.85 \pm 6.5 hours; $P<0.05]$. Sündermann et al.

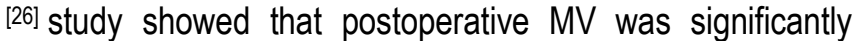
lower in minimally invasive mitral valve approach, and it may be due to less pain and minimal effect on mechanics of respiration.

We didn't observe any significant difference for the neurological complications between the two groups [three and two in groups $A$ and $B$ respectively]. The reduced surgical field and inadequate de-airing was set as the main causes for possible negative neurologic outcomes. Stroke had been reported to be higher with minimally invasive surgery, probably due to retrograde body perfusion during cardiopulmonary bypass [CPB]. This complication reported in about $2.6 \%$ of patients submitted for Mini-MVR. Nevertheless, a recent meta-analysis revealed that minimally invasive approaches were no longer associated with an increased risk of stroke ${ }^{[9]}$.

We didn't report any case with phrenic nerve injury, being matched with Mansy et al. [22] results. On right thoracotomy, the phrenic nerve must be well recognized to avoid its injury during the procedure.

Early postoperative arrhythmia and AF developed in eight patients of the study cohort [six in group $A$ and two in group $B, p=.49]$. Limited manipulation of the heart was associated with lower postoperative AF. Suri et al. [27] observed an equal AF rate between 350 isolated mitral valve repair performed with a mini-thoracotomy approach compared with 365 sternotomy operations [ $26 \%$ versus $27 \%, p=0.627$.
Post-operative pulmonary complications had a significant higher incidence in group [B]. In group [A], one patient developed pleural effusion and three had lung collapse; while in group $B$, two had lung congestion, three had effusions, eleven had atelectasis and three developed basal lung collapse $[p<0.05]$. Our patients had responded to conservative medical treatment. Mansy et al. [22] reported five patients at thoracotomy with right lung atelectasis and six patients with atelectasis at sternotomy group.

Renal complications were statistically non-significant between groups with two patients in each group requiring temporary dialysis for acute kidney injury. McCreath et al. [28] studied the issue of the acute kidney injury in relation to various approaches of cardiac surgery. They reported a high significant link between the surgical approach and the peak postoperative fractional creatinine change representing a higher risk of acute kidney injury with standard midline sternotomy access.

Two patients developed femoral area complications. The two patients had groin seroma and superficial groin wound infections. It is crucial to note that there is an extra-risk of groin comorbidities with the mini-mitral valve surgery. Such conditions are now added complications that are not present with the conventional sternotomy approach. Casselman et al. ${ }^{[29]}$ stated that femoral area complications are among the most common complications, and reported in 1 to $7 \%$ of cases.

The mean hours of intensive care unit [ICU] stay in group $[A]$ were significantly shorter than in group [B]. In a similar way, Ahmad Shah et al. [14] reported a significant shorter ICU stay with mini-thoracotomy than sternotomy $[17.1 \pm 4.2$ vs. $21.9 \pm 3.7$ hours; $\mathrm{P}<0.001]$. On the contrary, Mansy et al. [22] found comparable ICU duration of [1.32 \pm 0.4 ] days in thoracotomy versus $[1.41 \pm 0.7]$ days in sternotomy group. However, thoracotomy was superior to sternotomy regarding postoperative ICU and hospital stay $\left[{ }^{[1,30]}\right.$.

Regarding wound infection, Raslan et al. [23] reported significant difference regarding wound infection $[p=0.035]$. These results are in contradiction to the current study. However, Mansy et al. [22] showed that wound dehiscence absent and superficial infection was infrequent, as in the current study. Aybek et al. [19] and Ahmad Shah et al. [14] reported that minimally invasive mitral valve surgery was less prone to sepsis while sternal wounds were more vulnerable to it.

Patients of group $[A]$ reported significant lower pain score than patients in group $[B]$. The increasing pain level at sternotomy may be due to instability or friction of the divided sternum. Possible benefits of minimal invasive approach included lower pain and faster return to normal daily 
activities. In Mansy et al. [22] study, comparing right thoracotomy for mitral valve surgery with standard median sternotomy, the postoperative pain was high in sternotomy than thoracotomy group [4.3 \pm 2.1 versus $2.3 \pm 1.1, p<0.05$ ] and the need for analgesia was significantly higher in sternotomy group. Casselman and colleagues [29] reported that $93.5 \%$ of their patients had minimal to no pain related to the procedure after a mini-thoracotomy access.

Regarding patient satisfaction, McClure et al. [31] stated that the minimally invasive mitral valve surgery carried fewer complications and associated with increased patient satisfaction than the standard median sternotomy technique.

In general, our results are in line with previous studies. However, despite excellent outcome with minimal invasive surgery, criticism continuing regarding minimally invasive mitral valve surgery, due to its technical difficulty, complexity and its need for a distinct learning curve. Finally, for many cardiothoracic surgeons, the decision to use minimally invasive approaches for mitral valve surgery is more related to the aesthetic results than better clinical outcomes.

In a recent meta-analysis, Moscarelli et al. ${ }^{[32]}$ concluded that, minimally invasive and conventional sternotomy approaches produce comparable early and long-term results. The minimally invasive approaches were associated with prolonged cross-clamp and CPB times, but no harmful effects on the clinical outcomes. They recommend future researches to evaluate the effect of surgeon expertise and procedural volume on patient outcomes. Most recently, Cetinkaya et al. ${ }^{[6]}$ demonstrated that, minimally invasive surgery provided good results for MV surgery, achieving a high MV repair rate, low peri-procedural morbidity and mortality, and improved long-term outcome. It could replace conventional sternotomy as a standard approach for MV surgery.

\section{CONCLUSION}

In conclusion, the results of the current study add to the available evidence of the good short and mid-term outcome of minimal invasive approach for mitral valve surgery, as the conventional sternotomy. We advocate the use of such minimal invasive approach as the standard interventional surgical approach for mitral valve surgery. However, the small sample size of the current work is a limiting step that prevents globalization of the results.

\section{Financial and non-financial disclosure}

Authors declare that, nothing to disclose.

\section{REFERENCES}

1. Girdauskas E, Pausch J, Harmel E, Gross T, Detter C, Sinning $\mathrm{C}$, Kubitz J, Reichenspurner H. Minimally invasive mitral valve repair for functional mitral regurgitation. Eur J Cardiothorac Surg. 2019;55[Suppl 1]:117-i25. DOI: 10.1093/ejcts/ezy344.

2. Maier RH, Kasim AS, Zacharias J, Vale L, Graham R, Walker A, et al. Minimally invasive versus conventional sternotomy for Mitral valve repair: protocol for a multicentre randomised controlled trial [UK Mini Mitral]. BMJ Open. 2021 Apr 14; 11[4]:e047676. DOI: 10.1136/bmjopen-2020-047676.

3. Abu-Omar Y, Fazmin IT, Ali JM, Pelletier MP. Minimally invasive mitral valve surgery. J Thorac Dis. 2021 Mar;13[3]:1960-1970. DOI: $10.21037 /$ jtd-20-2114.

4. Atluri P, Stetson RL, Hung G, Gaffey AC, Szeto WY, Acker MA Hargrove WC. Minimally invasive mitral valve surgery is associated with equivalent cost and shorter hospital stay when compared with traditional sternotomy. J Thorac Cardiovasc Surg. 2016;151[2]:385-8. DOI: 10.1016/j.jtcvs.2015.08.106.

5. Hawkins RB, Mehaffey JH, Kessel SM, Dahl JJ, Kron IL, Kern JA, Yarboro LT, Ailawadi G. Minimally invasive mitral valve surgery is associated with excellent resource utilization, cost, and outcomes. J Thorac Cardiovasc Surg. 2018 Aug; 156[2]:611-616.e3. DOI: 10.1016/j.jtcvs.2018.03.108.

6. Cetinkaya A, Geier A, Bramlage K, Hein S, Bramlage $P$, Schönburg M, Choi YH, Richter M. Long-term results after mitral valve surgery using minimally invasive versus sternotomy approach: a propensity matched comparison of a large single-center series. BMC Cardiovasc Disord. 2021 Jun 26;21[1]:314. DOI: 10.1186/s12872-021-02121-3.

7. Onan B. Minimal access in cardiac surgery. Turk Gogus Kalp Damar Cerrahisi Derg. 2020 Oct 21;28[4]:708-724. DOI: 10.5606/tgkdc. dergisi.2020.19614.

8. Dokhan AL, Taher AH, Nashy MR, Elbaki MB. Early outcome of thoracoscopic minimally invasive versus conventional mitral valve surgery for mitral valve diseases. Menoufia Med J 2018; 31:1397-401. DOI: 10.4103/mmj.mmj_429_17

9. Cuartas MM, Davierwala PM. Minimally invasive mitral valve repair. Indian J Thorac Cardiovasc Surg. 2020 Jan; 36[Suppl 1]:44-52. DOI: 10.1007/s12055-019-00843-w.

10. Chen Y, Huang LC, Chen DZ, Chen LW, Zheng ZH, Dai XF. Totally endoscopic mitral valve surgery: early experience in 188 patients. J Cardiothorac Surg. 2021 Apr 17;16[1]:91. DOI: 10.1186/s13019-021-01464-4.

11. Calafiore AM, Totaro A, Testa N, Di Mauro M. Minimally invasive mitral valve repair: for every patient, for every surgeon or still a work in progress? J Thorac Dis. 2020 Apr;12[4]:16211623. DOI: $10.21037 /$ jtd.2020.02.39.

12. Hua M, Scales DC, Cooper Z, Pinto R, Moitra V, Wunsch H. 
Impact of Public Reporting of 30-day Mortality on Timing of Death after Coronary Artery Bypass Graft Surgery. Anesthesiology. 2017 Dec;127[6]:953-960. DOI: 10.1097/ ALN.0000000000001884.

13. Park JT. Postoperative acute kidney injury. Korean J Anesthesiol. 2017 Jun;70[3]:258-266. DOI: 10.4097/kjae.2017. 70.3.258.

14. Ahmad Shah Z, Ahangar AG, Ganie FA, Wani ML, Lone H, Wani $\mathrm{NU}$, et al. Comparison of right anterolateral thorocotomy with standard median steronotomy for mitral valve replacement. Int Cardiovasc Res J. 2013 Mar;7[1]:15-20. PMID: 24757613.

15. Saha H, Ranjan R, Adhikary D, Ahmed J, Saha S, Adhikary A. Early outcome of mitral valve replacement through right anterolateral thoracotomy versus standard median sternotomy. Bangabandhu Sheikh Mujib Medical University J. 2018; 11[1]: 94-98. DOI:10.3329/bsmmuj.v1111.35584

16. Ganie FA, Ahangar AG, Shah ZA, Lone GN, Lone H, Wani ML, et al. Right anterolateral thoracotomy a minimally invasive approach to mitral valve replacement. Muller J Med Sci Res. 2013; 4: 53-56. DOI: 10.4103/0975-9727.118223.

17. Dokhan AL, Mazen MH, Ibrahim IM, Girgis SW. Comparison of perioperative morbidity and mortality in minimally invasive versus conventional mitral valve surgery. Menoufia Med J 2019; 32: 599-603. DOI: 10.4103/mmj.mmj_767_17

18. El-Fiky MM, El-Sayegh T, El-Beishry AS, Abdul Aziz M, Aboul Enein $\mathrm{H}$, Waheid S, Sallam IA. Limited right anterolateral thoracotomy for mitral valve surgery. Eur J Cardiothorac Surg. 2000 Jun;17[6]:710-3. DOI: 10.1016/s1010-7940[00]00429-2.

19. Aybek T, Dogan S, Risteski PS, Zierer A, Wittlinger T, Wimmer-Greinecker G, Moritz A. Two hundred forty minimally invasive mitral operations through right minithoracotomy. Ann Thorac Surg. 2006 May;81 [5]: 1618-24. DOI: 10.1016/j. athoracsur.2005.12.006.

20. Tang P, Onaitis M, Gaca JG, Milano CA, Stafford-Smith M, Glower D. Right Minithoracotomy Versus Median Sternotomy for Mitral Valve Surgery: A Propensity Matched Study. Ann Thorac Surg. 2015 Aug;100[2]: 575-81. DOI: 10.1016/j. athoracsur.2015.04.027.

21. Murzi M, Cerillo AG, Miceli A, Bevilacqua S, Kallushi E, Farneti $P$, Solinas M, Glauber M. Antegrade and retrograde arterial perfusion strategy in minimally invasive mitral-valve surgery: a propensity score analysis on 1280 patients. Eur $\mathrm{J}$ Cardiothorac Surg. 2013 Jun;43[6]:e167-72. DOI: 10.1093/ejcts/ezt043.

22. Mansy MM, El-Zaki M. Mitral valve surgery through right thoracotomy versus median sternotomy: comparative study. J Egypt Soc Cardiothorac Surg 2010;18[1-2]:18.

23. Raslan S, Sharaa M, Refaie M, Ali WDK, Elhenawy AM. Outcome variables of right anterolateral mini-thoracotomy versus complete sternotomy in atrial septal defect closure: A randomized controlled trial. J Egy Soc Cardio-Thoracic Surg. 2017; 25[2]: 121-127. DOI: 10.1016/j.jescts.2017.03.004

24. Svensson LG, Atik FA, Cosgrove DM, Blackstone EH, Rajeswaran J, Krishnaswamy G, et al. Minimally invasive versus conventional mitral valve surgery: a propensity-matched comparison. J Thorac Cardiovasc Surg. 2010 Apr;139[4]:92632. e1-2. DOI: $10.1016 /$ j.jtcvs.2009.09.038.

25. El Ashkar AM, Khallaf AN. Video-Assisted Minimally Invasive Mitral Valve Surgery: Early Experience. J Egy Soc CardioThoracic Surg. 2016; 24 93]: 223-227. DOI: 10.1016/j.jescts. 2016.08.005.

26. Sündermann SH, Czerny M, Falk V. Open vs. Minimally Invasive Mitral Valve Surgery: Surgical Technique, Indications and Results. Cardiovasc Eng Technol. 2015 Jun;6[2]:160-6. DOI: $10.1007 / \mathrm{s} 13239-015-0210-5$.

27. Suri RM, Schaff HV, Meyer SR, Hargrove WC 3rd. Thoracoscopic versus open mitral valve repair: a propensity score analysis of early outcomes. Ann Thorac Surg. 2009 Oct;88[4]:1185-90. DOI: 10.1016/j.athoracsur.2009.04.076.

28. McCreath BJ, Swaminathan M, Booth JV, Phillips-Bute B, Chew ST, Glower DD, Stafford-Smith M. Mitral valve surgery and acute renal injury: port access versus median sternotomy. Ann Thorac Surg. 2003 Mar;75[3]:812-9. DOI: 10.1016/s00034975[02]04502-2.

29. Casselman F, Aramendi J, Bentala M, Candolfi P, Coppoolse $\mathrm{R}$, Gersak B, et al. Endoaortic Clamping Does Not Increase the Risk of Stroke in Minimal Access Mitral Valve Surgery: A Multicenter Experience. Ann Thorac Surg. 2015 Oct;100[4]:1334-9. DOI: 10.1016/j.athoracsur.2015.04.003.

30. Glauber M, Miceli A, Gilmanov D, Ferrarini M, Bevilacqua S, Farneti PA, Solinas M. Right anterior minithoracotomy versus conventional aortic valve replacement: a propensity score matched study. J Thorac Cardiovasc Surg. 2013 May;145[5]:1222-6. DOI: 10.1016/j.jtcvs.2012.03.064.

31. McClure RS, Cohn LH, Wiegerinck E, Couper GS, Aranki SF, Bolman RM 3rd, Davidson MJ, Chen FY. Early and late outcomes in minimally invasive mitral valve repair: an elevenyear experience in 707 patients. J Thorac Cardiovasc Surg. 2009 Jan;137[1]:70-5. DOI: 10.1016/j.jtcvs.2008.08.058.

32. Moscarelli M, Fattouch K, Gaudino M, Nasso G, Paparella D, Punjabi $P$, et al. Minimal Access Versus Sternotomy for Complex Mitral Valve Repair: A Meta-Analysis. Ann Thorac Surg. 2020 Mar;109[3]:737-744. DOI: 10.1016/j.athoracsur. 2019.07.034. 


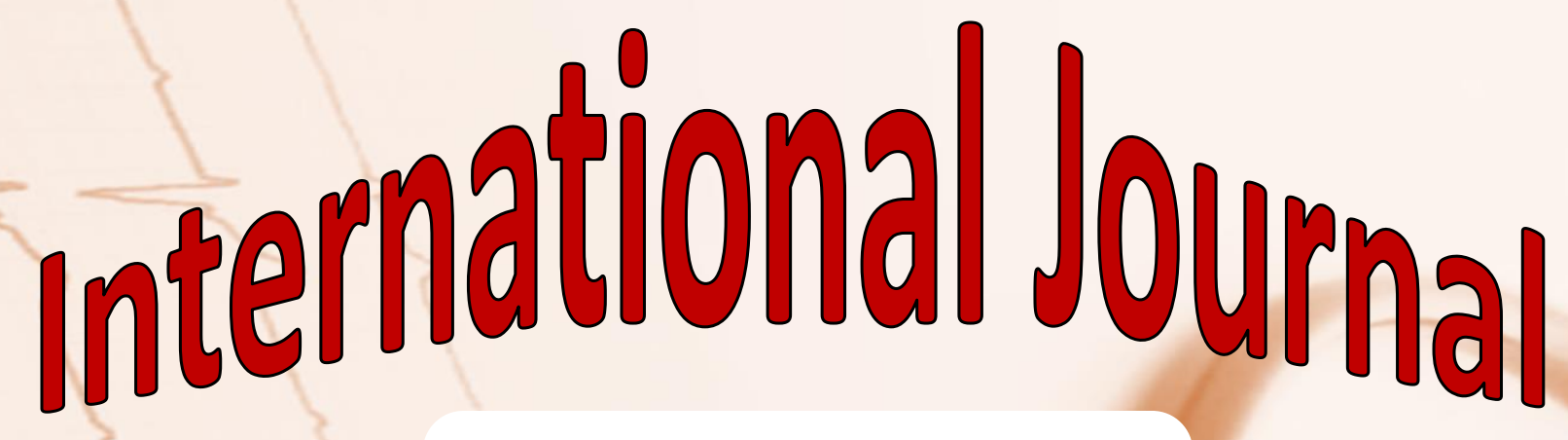

https://ijma.journals.ekb.eg/ Print ISSN: 2636-4174 Online ISSN: 2682-3780

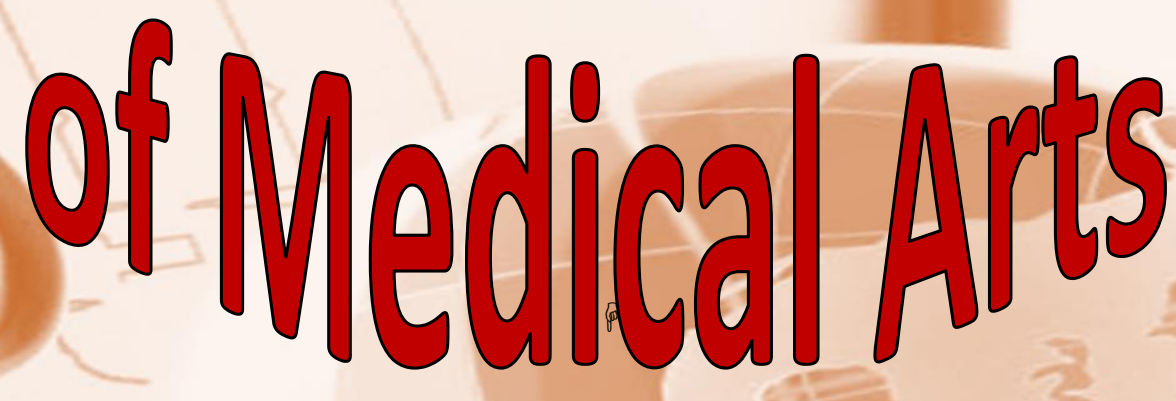

